\title{
Sero-Prevalence of Dengue at Laboratory Practice in Hyderabad
}

\author{
Haseeba Tanveer* and P. Nanda Kishore \\ Elbit Medical Diagnostics, 8-2-700/A, Road no 12, Banjara hills, \\ Hyderabad, Telangana state, 500034, India \\ *Corresponding author
}

\begin{tabular}{l} 
Key w or d s \\
$\begin{array}{l}\text { Dengue, Mosquito, } \\
\text { Hyderabad, ELISA, } \\
\text { NS1antigen, IG M } \\
\text { and IG G antibodies }\end{array}$ \\
\hline Article Info \\
\hline $\begin{array}{l}\text { Accepted: } \\
\text { 15 January } 2020 \\
\text { Available Online: } \\
\text { 10 February } 2020\end{array}$ \\
\hline
\end{tabular}

\section{A B S T R A C T}

Dengue is a mosquito-borne viral disease of global public health concern. As per national records there has been steady increase in cases every passing year Gupta $\mathrm{N}$ et al., 2012(3) An intense dengue infection swept hyderabad in 2019.Early diagnosis of dengue is important and canbe established with commercially available serological assays Chaturvedi UC et al., $2004{ }^{(1)}$.A total of 733 serum samples from suspected dengue cases were collected. Serological tests(ELISA )specific for dengue were performed. Of the 733 persons 299(40\%) were confirmed as having dengue infection either for NS1 antigen or for IgM, ig G antibody. Higher incidence of cases in males and in the age group of 20-30 years was seen. Dengue has traditionally been held to be a disease of high population density tropical urban areas Pavri KM et al., 1978, Teixeira MG et al., $2002^{(10,14) .}$ This is an effort to find out the prevalence of dengue among the patients attending ELBIT Medical Diagnostics, Banjara hills, Hyderabad. National level comprehensive studies to estimate the true burden of dengue in India and its geographical mapping are lacking. Such information would prove to be very critical in planning appropriate dengue prevention and control strategies

\section{Introduction}

Dengue is a mosquito-borne viral disease of global public health concern. The disease poses a threat to more than 1.8 billion people in the tropics and subtropical region infecting about 100 million people every year WHO $2009^{(17)}$. As per national records there has been steady increase in cases every passing year Gupta $\mathrm{N}$ et al., $2012^{(3)}$. The dengue viruses(DEN) that cause these clinical illnesses consist of four serotypes, DEN-1, -2, -3, and -4 Innis, B et al., 1989, kevin $\mathrm{r}$ et al., $1999^{(5,6)}$. The presence of four serotypes has become one of the complex challenges presented by dengue.

It may be asymptomatic or may lead to undifferentiated dengue fever (DF) or dengue hemorrhagic fever (DHF) and dengue shock syndrome WHO $1997^{(16)}$. DHF and dengue shock syndrome (DSS) are causes of 
hospitalization and death especially among children Lanciotti RS et al., 1992. Narayanan M et al., 2003 ${ }^{(7,9)}$. Early diagnosis of dengue is important and can be established with commercially available serological assays Chaturvedi UC etal $2004^{(1)}$. Early case detection and management reduce morbidity and mortality due to DHF and DSS

An intense dengue infection swept Hyderabad in 2019. Many suspected persons were referred by the local physicians to our laboratory (ELBIT Medical Diagnostics, Banjara hills, Hyderabad) for serological diagnosis of dengue. An opportunity was obtained to investigate, analyze and categorize the cases who were actually suffering from dengue. The main objective of present study was to create an impact, so that necessary measures be taken to further prevent dengue infection.

\section{Materials and Methods}

During the period between August and October 2019, A total of 733 serum samples from suspected dengue cases were collected. Serological tests requested by the physicians to diagnose dengue were dengue specific NS1 antigen and IgM and IgG antibodies by, ELISA (Pan Bio diagnostics). Either alone or in various combinations as stated below:

- Category 1 only NS1 antigen

- Category 2 only IgM antibody

- Category 3 NS1 antigen + IgM and IgG antibodies

- Category 4 only IgM and IgG antibodies

- Category 5 NS1 antigen and IgM antibodies

- Category 6 NS1 antigen and IgG antibodies

- Category 7 only IgG antibodies.

A primary infection is indicated when the $\mathrm{IgM}$ to $\mathrm{IgG}$ index value ratio is 1.78 and secondary infection is indicated when the $\operatorname{IgM}$ to $\mathrm{IgG}$ ratio is less than $1.78, \mathrm{M}$ Neeraja et al., 2006, Porter KR 1999, Cuzzubbo AJ et al., $1999^{(8,11.2) .}$

\section{Results and Discussion}

A total of 733 persons, suspected to be suffering from dengue were investigated, of whom 299(40\%) were confirmed as having dengue infection either for NS1 antigen or for IgM, Ig G antibody (Table 1). These comprised all age groups of both sexes with higher incidence of cases in males(chart 2) and in the age group of 20-30 years (Table 3 ). 78 (63.9\%), $82(3.4 \%), 5$ (18.7\%), 30(11.7\%), $28(2 \%), 5(0.3 \%)$ and $59(0.05 \%)$ were in Category 1, 2, 3, 4, 5, 6 and 7,respectively(Table 2).

Effective and accurate diagnosis of dengue is of primary importance for clinical care, early detection of severe cases, case confirmation and differential diagnosis WHO $2009^{(17)}$. To diagnose dengue, serological tests, such as dengue specific NS1 antigen and IgM and IgG antibodies are now often performed.

According to WHO $2009^{(17)}$ NS1 antigen can be detected up to 9 days after the onset of illness. IgM antibodies are detectable in 50\% of patients by days 3-5 after the onset of illness, increasing to $80 \%$ by day 5 and $99 \%$ by day 10 . IgM levels peak about 2 weeks after the onset of symptoms and then decline generally to undetectable level after 2-3 months WHO $2009^{(17)}$. To know the actual picture of the disease in a large scale, it is important to study the incidence of a particular disease in a region wise manner.

Laboratory criteria for confirmation of dengue fever are isolation of dengue virus from serum and detection of dengue and dengue hemorrhagic fever, virus genomic sequences by polymerase chain reaction WHO $1997^{(16)}$. 
Table.1 Prevalence of dengue

\begin{tabular}{|l|l|}
\hline Total specimens tested & 733 \\
\hline Positive for dengue & $299(40 \%)$ \\
\hline Negative for dengue & $437(60 \%)$ \\
\hline
\end{tabular}

Table.2 Morbidity due to dengue

\begin{tabular}{|c|c|c|}
\hline Category & ELISA & Remarks \\
\hline 1 (only NS1 antigen) & $88(29.4 \%)$ & early primary cases \\
\hline 2 (only IgM antibody) & $84(28 \%)$ & Late primary cases \\
\hline $\begin{array}{c}3 \text { (NS1 antigen + IgM and IgG } \\
\text { antibodies) }\end{array}$ & $5(1.6 \%)$ & late secondary cases \\
\hline 4 (IgM and IgG antibodies) & $30(10 \%)$ & late secondary cases \\
\hline 5 (NS1 antigen and IgM antibodies) & $28(9.3 \%)$ & Late primary cases \\
\hline 6 (NS1 antigen and IgG antibodies) & $5(1.6 \%)$ & Early secondary cases \\
\hline 7 (only IgG antibodies) & $59(19.7 \%)$ & $\begin{array}{l}\text { Old cases suffered } \\
\text { from dengue } \\
\text { previously }\end{array}$ \\
\hline
\end{tabular}

Table.3 Age wise distribution of dengue cases

\begin{tabular}{|c|c|c|}
\hline Age group(years) & Total cases & Positive \\
\hline $\mathbf{0 - 1 0}$ & $140(19 \%)$ & $51(17)$ \\
\hline $\mathbf{1 1 - 2 0}$ & $80(10 \%)$ & $32(10.7 \%)$ \\
\hline $\mathbf{2 1 - 3 0}$ & $198(27 \%)$ & $105(35 \%)$ \\
\hline $\mathbf{3 1 - 4 0}$ & $141(19 \%)$ & $57(19 \%)$ \\
\hline $\mathbf{4 1 - 5 0}$ & $66(9 \%)$ & $26(8.6 \%)$ \\
\hline $\mathbf{5 1 - 6 0}$ & $44(6 \%)$ & $10(3.3 \%)$ \\
\hline$>\mathbf{6 1}$ & $64(8.7 \%)$ & $18(6 \%)$ \\
\hline total & 733 & 299 \\
\hline
\end{tabular}

Table.4 Secondary dengue cases

\begin{tabular}{|c|c|}
\hline Total ig $M$ and ig G positives & $\begin{array}{c}\text { Ratio less than } 1.78 \\
\text { (secondary cases) }\end{array}$ \\
\hline $\mathbf{3 0}$ & $15(50 \%)$ \\
\hline
\end{tabular}




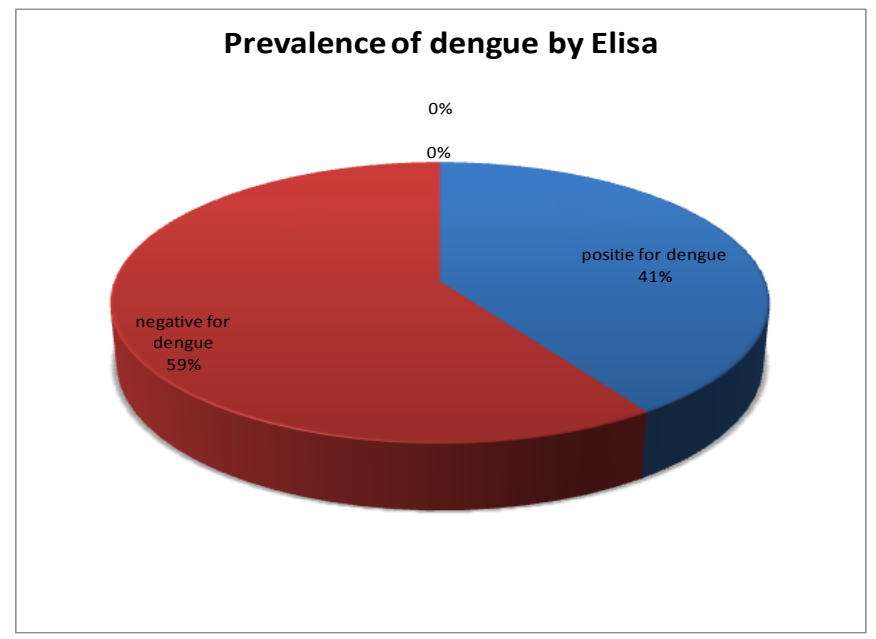

Chart.1 Prevalence of dengue

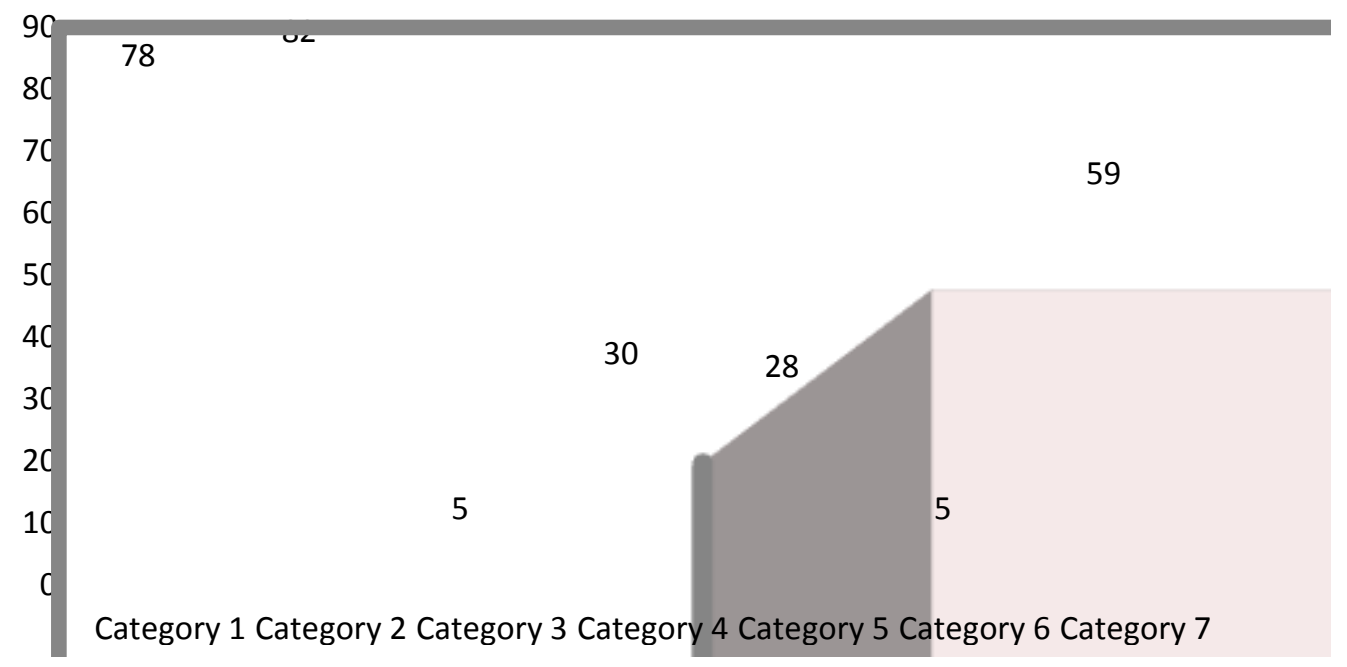

Chart.2 Morbidity due to dengue

However, these tests are available only in reference laboratories and not available routinely. Hence, serological tests that demonstrate a fourfold or greater rise in reciprocal $\operatorname{IgG}$ or IgM antibody titre to one or more dengue virus antigens in the serum have greatly enhanced our ability to effectively and efficiently diagnose dengue infection

The serological tests using IgM capture and IgG capture ELISA in which the cut off value of the Ig G is set to discriminate between high levels of $\operatorname{IgG}$ (characteristic of secondary dengue infections) and lower levels ig $\mathrm{g}$ (primary/past dengue) Cuzzubbo AJ $1999^{(2)}$.

Dengue has traditionally been held to be a disease of high population density tropical urban areas ${ }^{(10,14)}$. This is an effort to find out the prevalence of dengue among the patients attending ELBIT Medical Diagnostics, Banjara hills, Hyderabad. During the period from Aug 19 to Oct 19, 733 suspected cases of dengue were tested for dengue NS1 antigen or Dengue IgM, Ig G antibody. OF them, 40\% were laboratory confirmed dengue cases. 


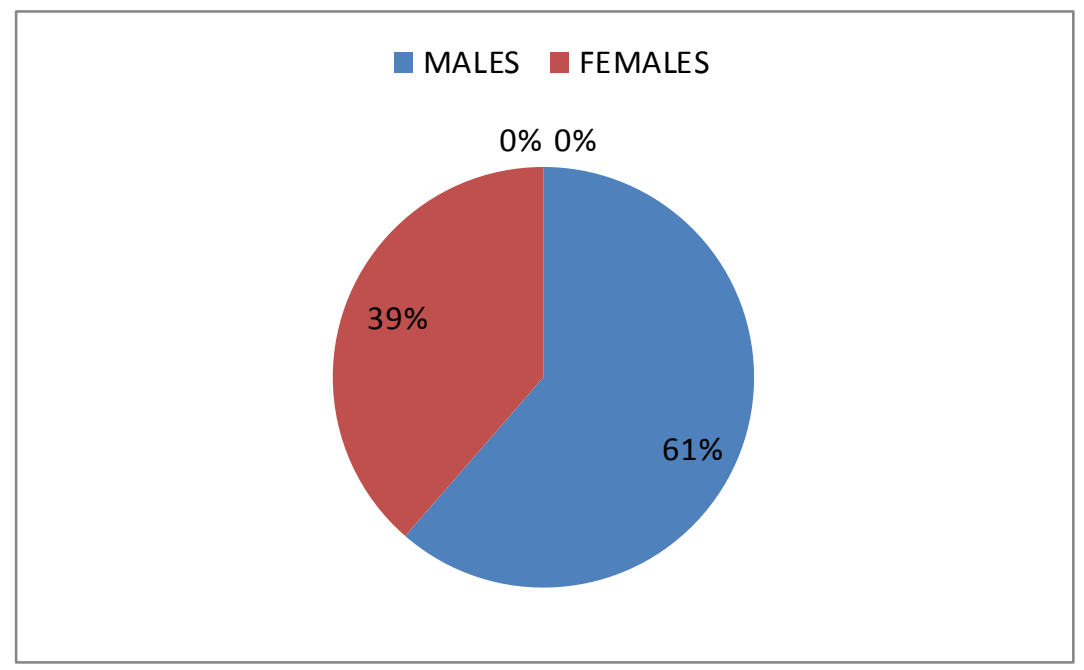

Chart.3 Gender wise distributions of cases

Amongst cases, 61\% (450/733) were male and $39 \%(283 / 733)$ belonged to female sex .of them 209/450 (70\%)among males are positive and 90/283(30\%) are positive for dengue .It has proven that males are found to be mostly affected as compared to female Several previous studies also supported that males are mostly at risk for carrying dengue infection as they are commonly engaged in outdoor activities.( Sharma J et al., 2013, 2017) ${ }^{(12,13)}$

A total of $27 \%(198 / 733)$ cases having suspected of dengue infection belonged to 21-30 years of age groups, of which 105/299 $(35 \%)$ are positives. This finding is in accordance with many previous studies (NVBDCP 2016, Sharma J et al., 2013, 2017, M Neeraja et al., 2006) ${ }^{(\mathbf{8 , 4 , 1 2 , 1 3 ) .}}$

Dengue in India has established its roots. Now it is endemic and almost hyperendemic in our population. National level comprehensive studies to estimate the true burden of dengue in India and its geographical mapping are lacking. Such information would prove to be very critical in planning appropriate dengue prevention and control strategies and also help in making decisions regarding suitable sites to undertake dengue vaccine clinical trials in future.

\section{Acknowledgement}

Authors are thankful to Mr. M.V. Anantha chary , CMD, Elbit medical diagnostics, Banjara hills Hyderabad for his keen interest, support, providing necessary facilities for this study

\section{References}

1. Chaturvedi UC, Shrivastava R. Dengue haemorrhagic fever: A global challenge. Indian J Med Microbiol 2004;22:5-6

2. Cuzzubbo AJ, Vaughn DW, Nisalak A, Solomon T, Kalayanarooj S, Aaskov J, et al., Comparison of PanBio dengue duo enzymelinked immunosorbent assay (ELISA) and MRL dengue fever virus immunoglobulin $\mathrm{M}$ capture ELISA for diagnosis of dengue virus infections in Southeast Asia. Clin Diagn Lab Immunol 1999;6:705-12.

3. Gupta N, Srivastava S, Jain A, Chaturvedi UC.Dengue in India. Indian Journal of Medical Research 2012;136:373-90

4. India, Ministry of Health and Family Welfare. National Vector BorneDisease Control Programme. New Delhi: Directorate General of Health Services; 2016. Available from: http://www.nvbdcp.gov.in. [Last accessed 
on 2016 Jan 08].

5. Innis, B. L., A. Nisalak, S. Nimmannitya, S. Kusalerdchariya, V. Chongswasdi, S. Suntayakorn, P. Puttisri, and C. H. Hoke. 1989. An enzyme-linked immunosorbent assay to characterize dengue infections where dengue and Japanese encephalitis co-circulate. Am. J. Trop. Med. Hyg. 40:418-427

6. kevin r. Porter, susana widjaja et al., clinical and diagnostic laboratory immunology, 1071-412X/99/ $\$ 04.0010$ Sept. 1999, p. 741-744 Vol. 6, No. 5 Evaluation of a Commercially Available Immunoglobulin $\mathrm{M}$ Capture EnzymeLinked Immunosorbent Assay Kit for Diagnosing Acute Dengue Infections.

7. Lanciotti RS, Calisher $\mathrm{CH}$, Gubler DJ, Chang GJ, Vorndam AVRapid detection and typing of dengue viruses from clinical samples by using reverse transcriptasepolymerase chain reaction. $J$ Clin Microbiol 1992;30:545-51

8. M Neeraja, *V Lakshmi, VD Teja, P Umabala, MV Subbalakshmi Serodiagnosis of dengue virus infection in patients presenting to a tertiary care hospital. Indian Journal of Medical Microbiology, (2006) 24 (4):280-2

9. Narayanan M, Aravind MA, Ambikapathy P, Prema RJeyapaul MP. Dengue fever: Clinical and laboratory parameters associated with complications. Dengue Bull 2003;27:108-15.

10. Pavri KM. Ecology of Mosquito Borne Viruses in India and Southeast Asia. In: Loutit MW,Miles JAR. Eds. Microbial
Ecology.Berlin.1978.

11. Porter KR, Widjaja S, Lohita HD, Hadiwijaya SH, Maroef CN, Suharyono $\mathrm{W}$, et al., Evaluation of a commercially available immunoglobulin $\mathrm{M}$ capture Enzyme-Linked Immunosorbent assay kit for diagnostic acute dengue infections. Clin Diagn LabImmunol 1999;6:741-4.

12. Sharma J. Clinico-epidemiological profile of dengue cases prevalent in lakhimpur district of Assam. Indian J MedMicrobiol 2017;35:148-9.

13. Sharma J, Malakar M, Soni M, Dutta P, Khan SA. Comparison ofdiagnostic performance of different kits for detection of acute dengue infection during an outbreak in Lakhimpur district of Assam. IndianStreams Res J 2013;3:1- 4.

14. Teixeira MG, Barreto ML, Costa MCN, DenizeL, Ferreira A, Vasconcelos PFC, et al., Dynamics of Dengue Virus Circulation: A Silent Epidemicin a Complex Urban Area. Tropical Medicine and International Health 2002;7:757-62.

15. Tripathi $\mathrm{P}$, Kumar R, Tripathi S, Tambe JJ,Venkatesh V. Descriptive Epidemiology of Dengue Transmission in Uttar Pradesh. Indian Pediatrics 2008;45:315-8.

16. WHO Dengue haemorrhagic fever, Diagnosis, Treatment, prevention and control. 2nd ed. Chapter 2. World Health Organization: Geneva, Switzerland; 1997.

17. World Health Organization (WHO) and the Special Programme for Research and Training in Tropical Diseases (TDR). Dengue: guide lines for diagnosis, treatment, prevention and control 2009.

\section{How to cite this article:}

Haseeba Tanveer and Nanda Kishore. P. 2020. Sero-Prevalence of Dengue at Laboratory Practice in Hyderabad. Int.J.Curr.Microbiol.App.Sci. 9(02): 2203-2208. doi: https://doi.org/10.20546/ijcmas.2020.902.248 